\title{
Casting and Applications of Functionally Graded Metal Matrix Composites
}

\author{
Williams S. Ebhota and Tien-Chien Jen \\ Additional information is available at the end of the chapter \\ http://dx.doi.org/10.5772/intechopen.71225
}

\begin{abstract}
This chapter discusses the concepts, casting techniques and applications of functionally graded materials metal matrix composites (FGMMCs). Considerations were given to bulk functionally graded aluminium matrix composites (FGAACs) production processes. Liquid-metal forging processes of FGAACs fabrication, such as infiltration process, squeeze casting, friction casting or compocasting, stir, and centrifugal casting were discussed. The chapter provides basic concepts of the processes and overview of their processing parameters, such as mould rotational speed; reinforcement particles size and volume; degassing method; melting and pouring temperatures; pressure; and stirrer. The study notes that functionally graded materials (FGMs) are commonly used in automotive, aircraft, aviation, chemical, medical, engineering, renewable energy, nuclear energy, and optics electronics industries.
\end{abstract}

Keywords: FGMMCs, aluminium matrix, FGMs fabrication techniques, centrifugal casting, stir casting, ceramics reinforcements, squeeze casting, infiltration process, compocasting

\section{Introduction}

Man has always found materials critical to his existence and advancement. As time progresses, he is often faced with challenges that usually change his opinion and ways of doing things. Material is not left out in this evolution, which most times facilitates the improvement of knowledge and technology. Value addition to engineering natural materials became desirable in man's quest to add more meaning to both his life and those of the people around him. This is a result of the dissatisfaction and challenges that accompanied the use of materials in their natural forms. The engineering of materials for specific characteristics dates as far back 
as $1000 \mathrm{BC}$, in which straw and mud were used as forms of composites [1]. Refinement of these composites have advanced over time; for example, fibre glass reinforced plastics composites, which are more superior, were introduced four decades ago. In very little time, many limitations were found in fibre reinforced plastics, the majority of problems being attributed to delamination. This delamination shortcoming, coupled with the need of materials to satisfy functional requirements, led to another breed of advanced materials: functionally graded materials (FGMs). The advent of FGMs was a major breakthrough in addressing material properties abrupt change in traditional composite, associated with large inter-laminar stresses leading to delamination [2]. These heterogeneous materials with gradually varied properties have replaced homogenous materials in some critical applications. The base (matrix) material of FGM can be metal or non-metal. Metallic matrix FGM is termed as functionally graded metal matrix composites (FGMMCs). Engineers and scientists are increasingly interested in the research and fabrication of heterogeneous FGMMCs for specific use.

This group of materials can be categorised as advanced materials in the family of engineering composites. Functionally graded material comprises of two or more component phases with continuous and gradually changing composition [3,4]; they are characterised by continuous transitions in the material's microstructure and composition in a specific direction [5]. FGM gradually vary over volume in both microstructure and composition, resulting in subsequent alterations in the material properties.

\subsection{Types of FGMs}

Functionally graded materials can be classified based on the material gradient types, as shown in Figure 1: fraction gradient, shape gradient; orientation gradient; and size gradient.

Functionally graded material structural unit is regarded as a material ingredient or element. Material ingredients are like biological cells such as tissues and other examples are presented in Table 1.

Although the type of this advanced material was developed by engineers and scientists, FGMs are also found in nature. Examples of naturally occurring FGMs are bone, teeth, bamboo and tree human skin. The grading of the human bone is shown in Figure 2.

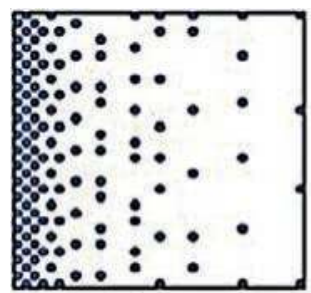

(a)

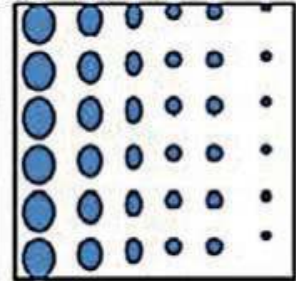

(b)

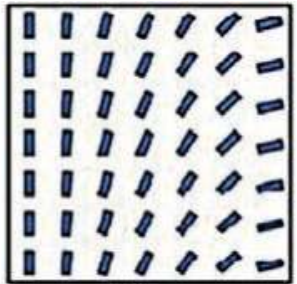

(c)

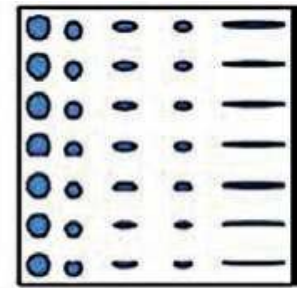

(d).

Figure 1. Types of FGMs based on gradient: (a) gradient with fraction; (b) gradient with size; (c) gradient with orientation; and $(\mathrm{d})$ gradient with shape [2]. 


\begin{tabular}{ll}
\hline Chemical & Inorganic, organic, ceramic, metal, and polymer \\
Physical & $\begin{array}{l}\text { Electronic state, ionic state, crystalline state, dipole movement, magnetic movement, band } \\
\text { gap, potential well, and barrier }\end{array}$ \\
Geometrical & Granule, rod, needle, fibre, platelet, sheet, pole, texture, and orientation \\
Biological & Complex macromolecule, organelle, cell, and tissue
\end{tabular}

Table 1. Various material ingredients that can compose FGMs [6].

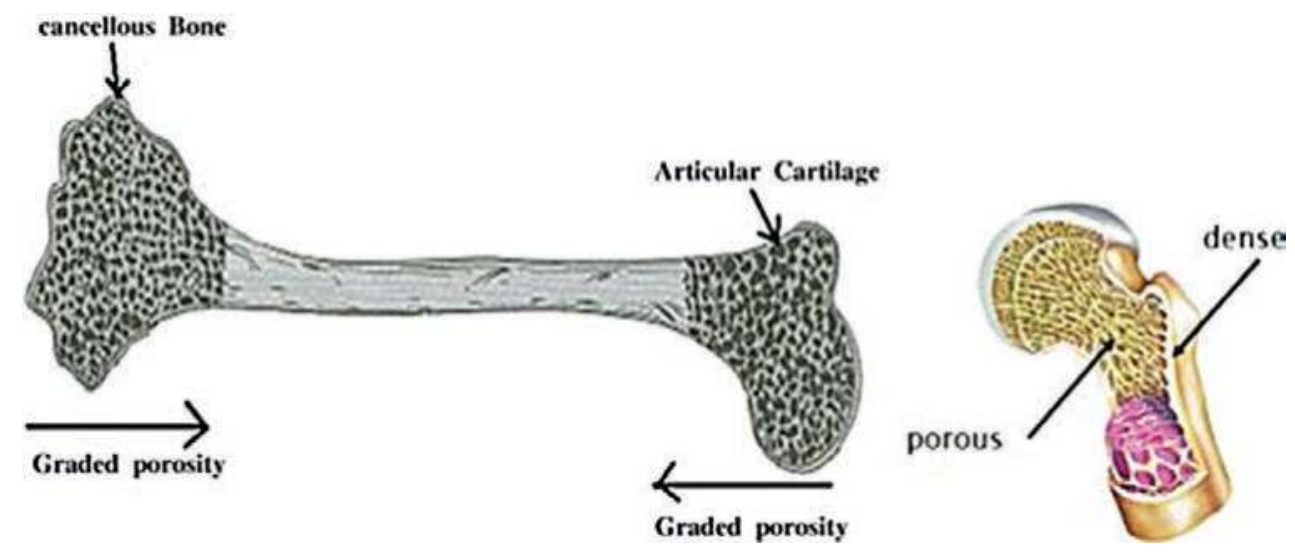

Figure 2. The naturally occurring FGMs human bone.

\section{Historical background}

\subsection{Evolution of FGMs}

Functionally graded materials were originally presented as a group of superior composite materials with a single continuous or discontinuous inclination with regard to composition and microstructure as shown in Figure 3 [7, 8]. The concept of structural gradients was first developed from composites and polymeric materials in 1972. Different methods of applying gradients in in filament concentration, composition and in polymerisation, coupled with application areas of graded structures were proposed. Though many of FGMs' principle theoretical studies were reported in the 1970s, the influence of these works was not felt proportionately. This was due to the inadequate actual investigative studies on the manufacturing techniques and evaluation of the graded structures.

Present day FGMs were developed from the study of composites and polymeric material in 1972 by Bever and Duwez. The study investigated the properties of global material and reevaluated the potential application of graded composites [10,11]. In the same year, Shen and Bever studied the structure and properties of polymeric materials having spatial gradients 


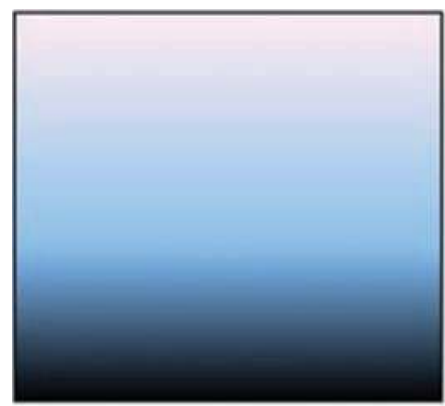

(a)

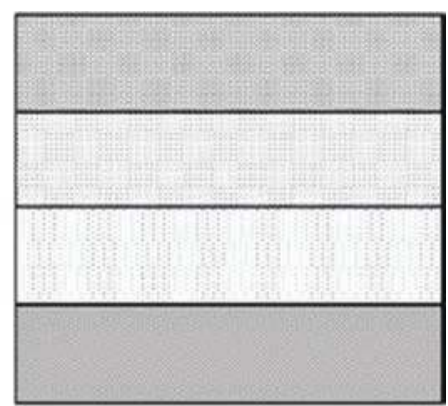

(b)

Figure 3. Functionally graded material structure types: (a) continuous and (b) discontinuous [9].

and their potential applications. The study declared that alteration of the chemical formation of monomers, morphology or supramolecular structure and the molecular makeup of the polymers may affect the graduation of polymeric material. However, the study failed to consider the design, fabrication and evaluation of the gradient of the structure [10].

The development of modern day FGMs began in the mid-1980s in Japan. The Japanese engineers were confronted with difficulty in finding a material suitable for a particular barrier in a space project, hypersonic plane. The barrier requires a thickness less than $10 \mathrm{~mm}$ and thermal working conditions of $1000 \mathrm{~K}$ and $2000 \mathrm{~K}$ of inside and outside temperatures respectively. This necessity pushed the engineers to FGM fabricate the barrier using FGM concept [12]. In the development of ceramic coatings and joints for the reusable rocket engine, the application of continuous texture control was suggested in 1985 [13]. This is to minimise the thermal stress and to increase the adhesion strength. These types of graded materials were named functionally gradient materials in 1986, which later became functionally graded materials with acronym FGM. The first FGMs national symposium was organised in Sendai, Japan in 1990 [14]. From 1987 to 1991, the FGM technology became very popular and several production techniques were developed. The early manufacturing processing methods include chemical vapour deposition (CVD), plasma spraying, powder metallurgy, self-propagating high-temperature synthesis (SHS), and galvanoforming. Since 1991 to the present date, these earlier FGM processing methods have been re-evaluated and modified and new one developed. These fabrication techniques have been categorised in various ways by several authors. Miyamoto et al. in 1999, grouped the processes into four main categories: layer, melt, bulk and preform processes [6]. These FGM techniques of production eliminated traditional composite delamination problem, caused by the sharp interface that is mainly responsible for the failure in the composites.

\subsection{Functionally graded materials (FGMMCs)}

Functionally graded metal matrix composites (FGMMCs) belong to a group of advanced material termed functionally graded materials (FGMs). The uniqueness of FGMs is that they smoothly change properties and composition spatially and vary from any single material that form them. They are materials that are specially engineered in a controlled manner for specific 
mechanical or chemical properties for both harsh working environments and optimal performance. This category of high performance materials is described as knowledge-based multifunctional materials (KMMs). They are applied in thermomechanical and high impact loading, high strain rates, high temperature, and aggressive chemical environments. Such environments are associated with turbomachinery, aerospace, automotive, chemical, microsensors, electronic devices, biological implants, and household appliances. Functionally graded materials are a major category of KMM materials. Functionally metal matrix composites (FGMMCs), such as $\mathrm{Al}-\mathrm{Si}-\mathrm{SiC}$, possess both high wear resistance and high bulk toughness. The structure of FGMMC is continuously or discretely altering the mechanical and thermal properties at the macroscopic or continuum scale. These spatially varied properties are achieved by varying certain process parameters of the reinforcements, such as type, size, shape, and dispersion pattern.

\section{Concept of FGMMCS}

This category (FGMMCs) of materials was an offshoot of the traditional composite materials, considered as advanced engineering materials. Composites are normally formed by combination of two or more different materials with individual physical and chemical properties in solid forms. However, composite material is characterised by an abrupt interface and a weak interfacial bond between the combining materials. This results in sharp property changes and, as a consequence, eventual failure under harsh working conditions, such as high temperature and high impact load. This failure is attributed to disintegration of reinforcement from the matrix; this type of failure is called delamination [15]. The sharp interface and the gradual change of a traditional composite and FGM are shown in Figure $\mathbf{4 a}$ and $\mathbf{4 b}$, respectively. The differences between composite and FGM are presented in Table 2.

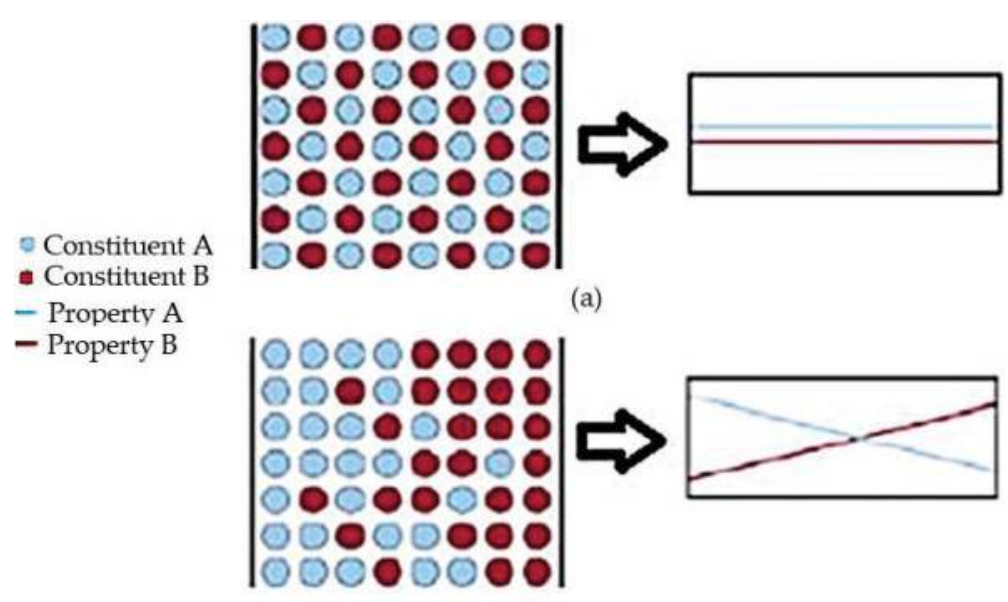

(b)

Figure 4. Material of two phases [16]: (a) traditional composite-constant composition and properties; (b) FGMgradual change in composition and microstructure gives a gradient in properties. 


\begin{tabular}{ll}
\hline Traditional composite & FGM \\
\hline $\begin{array}{l}\text { Abrupt interface between combining materials, causes sharp } \\
\text { properties change }\end{array}$ & Smooth transition between combining materials \\
Delamination occurs under extreme working conditions & $\begin{array}{l}\text { Very good interfacial bond between materials, so } \\
\text { delineation is avoided }\end{array}$ \\
$\begin{array}{l}\text { Matrix charge, weakness and strength of the combining } \\
\text { materials are equally distributed }\end{array}$ & $\begin{array}{l}\text { Properties of the combining materials are spatially } \\
\text { distributed is possible }\end{array}$ \\
$\begin{array}{l}\text { All the part is a bit thermal conductive and the matrix lost a } \\
\text { bit of hardness }\end{array}$ & $\begin{array}{l}\text { One side is largely hard and the other side is } \\
\text { largely thermal conductive }\end{array}$ \\
\hline
\end{tabular}

Table 2. The differences between composite and FGM.

The concept of FGM substitutes the abrupt interface of traditional composite materials with gradually changing interface and this eliminates the shortcomings that accompany the sharp interface. Subsequently, the chemical composition is altered at the interface, which ultimately improves the mechanical properties of the composite. Properties of FGM vary spatially; they are locationdependent in the bulk structure of the material. Functionally graded materials are engineered to possess changing properties, such as varying magnetic, thermal, mechanical, chemical composition, and electrical properties, changing microstructural and atomic arrangement. Figure 5 shows the model of FGM object gradient, bi-linear material variation and thermal stress relaxation.

\subsection{Production methods of FGMs}

The development of FGMs production methods witnessed a tremendous push in the last two decades, resulted in several FGMs fabrication methods, as presented in Table 3. These production methods are in both chemical and mechanical forms, and their applications are guided by the type/state of raw materials, facility availability and functional properties

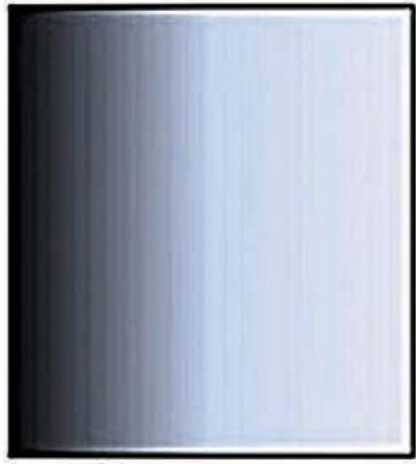

(a)

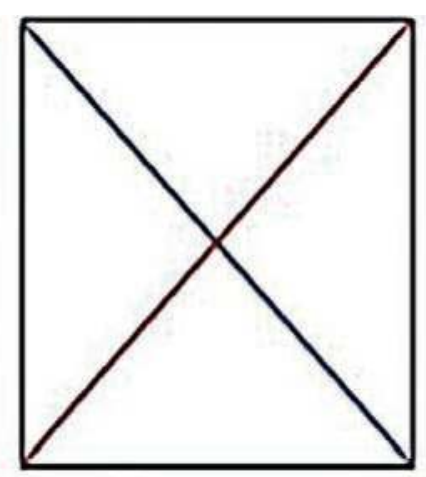

(b)

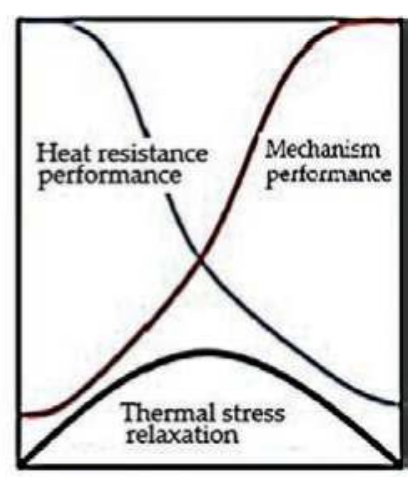

(c)

Figure 5. Model of FGM (a) FGMs object; (b) bi-linear material variation; and (c) thermal stress relaxation [2]. 


\begin{tabular}{|c|c|c|}
\hline Method & Type & $\begin{array}{l}\text { Group of } \\
\text { FGM }\end{array}$ \\
\hline Vapour deposition technique & $\begin{array}{l}\text { Chemical vapour deposition (CVD) and physical vapour } \\
\text { deposition (PVD) }\end{array}$ & $\begin{array}{l}\text { Thin surface } \\
\text { coating }\end{array}$ \\
\hline Powder metallurgy (PM) & $\begin{array}{l}\text { Stepwise Compositional Control: powder stacking, sheet } \\
\text { lamination and wet powder spraying } \\
\text { Continuous composition control: centrifugal powder forming } \\
\text { (CPF), impeller dry blending, centrifugal sedimentation, } \\
\text { electrophoretic deposition and pressure filtration/vacuum slip } \\
\text { casting }\end{array}$ & Bulk \\
\hline Melting processes & $\begin{array}{l}\text { Centrifugal casting, sedimentation casting infiltration processing, } \\
\text { thermal spray processing }\end{array}$ & Bulk \\
\hline $\begin{array}{l}\text { Material prototyping/solid } \\
\text { freeform (SFF) Fabrication }\end{array}$ & $\begin{array}{l}\text { Laser based processes: laser cladding, melting, laser sintering, } \\
\text { selective 3D-printing and selective laser }\end{array}$ & Bulk \\
\hline Other methods & $\begin{array}{l}\text { Plasma spraying, electrodeposition, electrophoretic, ion beam } \\
\text { assisted deposition (IBAD), self-propagating high-temperature } \\
\text { synthesis (SHS) }\end{array}$ & Thin coating \\
\hline
\end{tabular}

Table 3. FGM fabrication methods and their applications [18-21].

required. This development led to the emergence of many attractive engineering materials applied in the automotive and aviation sectors. These methods may be broadly categorised into the following [17]:

Constructive process: in this process the engineer determines the phase replacement within the formation.

Transport based process: This process depends on an appropriate and the created in situ reactions of processes during material production.

Also, FGMs are categorised based on products thickness or size into [4, 22]:

i. Thin FGM: Thin FGMs are relatively thin surface coatings or thin sections, formed by chemical or physical vapour deposition (CVD/PVD), self-propagating high-temperature synthesis (SHS), plasma spraying, etc.

ii. Bulk FGM: Bulk FGMs are fabricated by the following methods centrifugal casting, powder metallurgy, squeeze casting, solid freeform technology etc.

Constituents are the basic building cellblocks of a FGM, made up of matrix, particulates, interphase, precipitates and any other additives, which are identified in the material's microstructure. Constituents in FGM structure are usually described by their chemical composition, volume fraction, size, morphology and orientation within the material. In a broader perspective, FGM is formed by the combination of at least two different materials, which may be metal-metal, metal-ceramic, polymer-ceramic, etc. The structure of FGM is broadly divided into two, the matrix and the reinforcement. 


\subsection{FGM matrix}

The matrix is a monolithic material that forms the surrounding medium or structure, while the reinforcement is the constituent embedded in the matrix. Non-metal and metal matrices form functionally graded non-metal matrix composites (FGMMCs) and functionally graded metal matrix composites (FGNMMCs) respectively. Plastics, polymers and light metals such as aluminium, magnesium, brace, bronze, and titanium are widely used matrices for composite. Cobalt and cobalt-nickel alloy matrices are usually used in elevated temperature applications.

\subsection{Reinforcement}

Reinforcement is a material embedded in a matrix, which provides the material with the needed structural and physical properties, such as friction coefficient, wear resistance, thermal conductivity, etc. [23]. The reinforcement can be classified into continuous and discontinuous. Standard metalworking techniques, such as forging, extrusion, or rolling can be used to work on discontinuous FGMMCs that are isotropic (uniform in all orientations). Further, polycrystalline diamond tooling (PCD) is required to machine isotropic discontinuous MMCs using conventional techniques. Continuous reinforcement applies monofilament and form anisotropic structure in FGMs. This reinforcement alignment plays a role the strength behaviour of the material. Single, defect-free crystal filament of material is known as monocrystalline whisker. Whisker materials, having very high tensile strength (10-20 GPa), such as graphite, silicon-carbide, silicon, alumina and iron are commonly used as reinforcements in FGMMCs. Table 4 presents other FGM reinforcements that are used.

\subsection{Hybrid composite}

In a MMC, there are at least two constituents: one material is a metal matrix, and another a reinforcement, which can be metal or a non-material. A metal matrix composite formed by two different or more reinforcements is termed hybrid composite. Examples of hybrid composites are Al6061-SiC-Graphite, Al6061-SiC-TiB ${ }_{2}$ CNTs-Mg-Al, Al6061-SiC-MWCNT, etc., where $\mathrm{SiC}$ is silicon-carbide; MWCNT is multiwall carbon nanotubes; $\mathrm{TiB}_{2}$ is titanium diboride; and CNTs is carbon nanotubes. CNTs-Mg-Al and Al6061-SiC-MWCNT are also called metal matrix nanocomposites.

\begin{tabular}{ll}
\hline Metal matrix & Reinforcement \\
\hline Aluminium & Nitrides: $\mathrm{BN}, \mathrm{ZrN}, \mathrm{TiN}$ \\
Brace & Carbides: $\mathrm{SiC}, \mathrm{TiC}, \mathrm{ZrC}$ \\
Bronze & Borides: $\mathrm{ZrB}_{2^{\prime}} \mathrm{TiB}_{2^{\prime}}, \mathrm{SiB}_{2}$ \\
Titanium & Oxides: $\mathrm{Al}_{2} \mathrm{O}_{3^{\prime}}, \mathrm{MgO}, \mathrm{TiO}_{2^{\prime}}, \mathrm{ZrO}_{2}$ \\
Magnesium & Silicides: $\mathrm{MoSi}_{2}$ \\
Cobalt & Intermetallic: $\mathrm{Fe}_{3} \mathrm{Al}, \mathrm{FeAl}, \mathrm{NiAl}, \mathrm{Ni}_{3} \mathrm{Al}, \mathrm{Ti}_{3} \mathrm{Al}, \mathrm{TiAl}$ \\
\hline
\end{tabular}

Table 4. Metal matrices and reinforcing materials used in FGMMCs. 


\section{Functional graded aluminium alloy matrix composites (FGAAMCS)}

Basically, FGMMC composed of metal matrix phase and reinforcement phase, such that the elastic modulus and hardness differ from the metallic phase to the ceramic phase. In this chapter, FGMs formed by aluminium alloy matrix and ceramic particles reinforcements are regarded as functionally graded aluminium alloy matrix composites (FGAACs). Since the Japanese engineers' breakthrough in the hypersonic space plane project in the 1980s, several investigative studies on FGAACs have been performed and reported. Studies on the different aspects of FGAACs are ongoing, which include design of the different composition, characterisation, modelling, optimisation and development of FGMs fabrication techniques [24-28].

\subsection{Fabrication techniques of FGAACs}

Over the years, several FGAACs production techniques - that is, the processes of combining aluminium alloy with ceramic material-have been designed, developed and used. Despite the various FGAACs achievements that have been reported, further development is still expected. The increase need for FGAACs is due to the lightweight materials demands from the rapidly growing industrial applications of FGMs in the automotive and aerospace industries [29-31]. Apart from the lightweight advantage, the possibility of determining the mechanical and chemical properties of FGAACs, through the alteration of microstructure, also account for the growing interest. Production of a material with high wear resistance at a high temperature is possible by reinforcing the matrix with ceramic material along the part where bulk toughness required [32].

Among the various FGM fabrication techniques, the melting/casting based processes, (Table 5 refers), will be discussed in this chapter. These techniques include the squeeze casting method, centrifugal casting method, sedimentation casting infiltration, vibration casting, compocasting, stir casting, sequence casting, and pressure casting.

\subsection{Squeeze casting}

Squeeze casting technique (SCT) is a liquid-metal forging method that involves the solidification of liquid metal under pressure in a closed dies placed in between hydraulic press plates.

\begin{tabular}{ll}
\hline Parameters & Range \\
\hline $\begin{array}{l}\text { Casting temperatures }- \text { depend on the part geometry } \\
\text { and the alloy. }\end{array}$ & $6-55^{\circ} \mathrm{C}$ above the liquidus temperature \\
Tooling temperatures ranging & $190-315^{\circ} \mathrm{C}$ \\
Pressure levels & $50-140 \mathrm{MPa}$ \\
Pressure duration & Varying from 30 to $120 \mathrm{~s}$ \\
$\begin{array}{l}\text { Lubrication-for aluminium, magnesium, and copper } \\
\text { alloys }\end{array}$ & $\begin{array}{l}\text { Spray of good grade of colloidal graphite lubricant on the } \\
\text { warm dies prior to casting. }\end{array}$ \\
\hline
\end{tabular}

Table 5. Squeeze casting parameters [34-37]. 
This process creates a fast heat transfer scenario that produces a fine-grain and pore-free casting. The casting mechanical properties are similar to that of a wrought product. Squeeze casting process has been classified into four basic steps in the fabrication of FGMs by Ghomashchi and Vikhrov in a review study as follows [33]: pouring of a molten metal into the mould, closing the mould, application of pressure and cast ejection. A more detailed series of operational step is depicted in Figure 6.

However, for quality casting, these following processing variables should be considered in squeeze casting method: melting temperature (Tm), degassing method, die temperature (TD), delay time $(\mathrm{tD})$, pouring temperature $(\mathrm{Tp})$, applied pressure $(\mathrm{P})$ and humidity $(\mathrm{Hd})$. Additional parameters to consider in the case of FGMMCs fabrication include the temperature of the ceramic particles (Tc), the rate of at which particles are added to the molten metal (ta), stirring time (ts) and speed (tv) of the mixture. Values for some of the SCT parameters are presented in Table 5. In the squeeze casting method, casting properties, such as hardness, density, and secondary dendrite arm spacing, depend mainly on the effects of these processing parameters. Figure 6 shows the input-output model of a SCT.

The many advantages of SCT rest in its production of casting with low gas porosity and shrinkage; improved mechanical properties through rapid solidification; good surface quality and performance of good preformation infiltration. The process can be automated to yield near net shape, high-quality parts, with minor post production processes. Squeeze casting technique is widely used for the fabrication of aluminium, magnesium alloys and FGMMCs. A schematic of SCT die set-up is shown in Figure 7.

\subsection{Infiltration method}

Infiltration is one of the FGMMCs fabrication techniques, which involves the soaking of a preformed dispersed phase (fibres, particles, woven) in a molten metal. This is to allow the spaces between the dispersed phase inclusions to be filled. Infiltration requires two stages: initiation of flow depicted by the dynamic wetting angle, and advancing the flow in the preform capillaries.

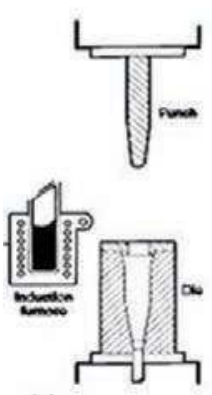

(a)

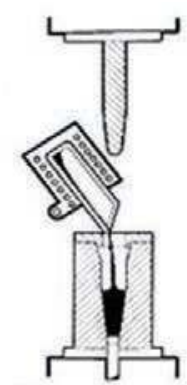

(b)

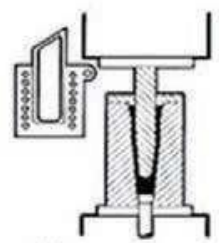

(c)

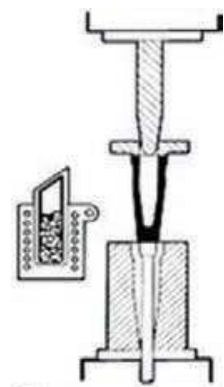

(d)

Figure 6. Schematic in squeeze casting process operations [34]: (a) melt charge, preheat and lubricate tooling; (b) pour melt into the die cavity; (c) close tooling, allow melt to solidify under pressure; and (d) ejecting the casting, and felting and die cleaning. 

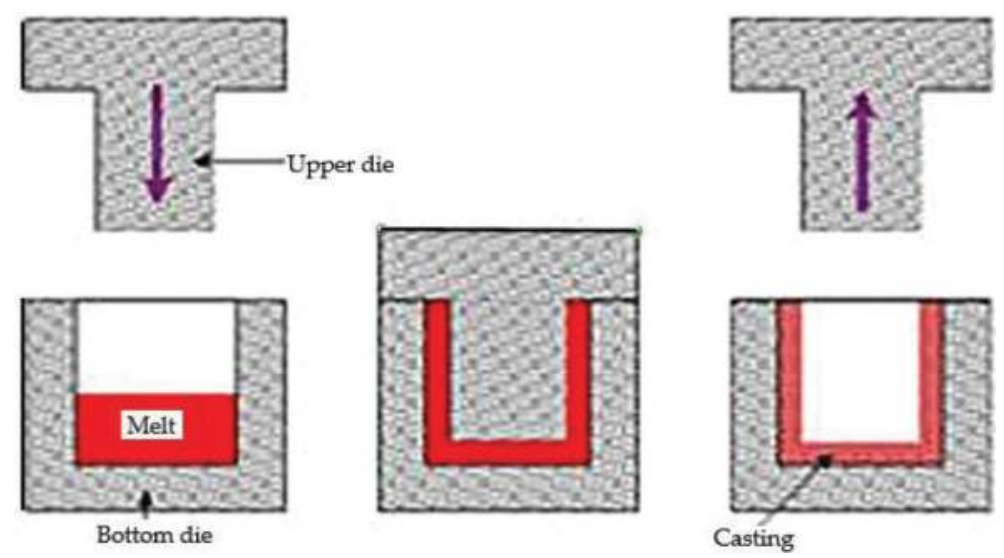

Figure 7. Schematic of SCT die set-up for melt [38].

Infiltrating a preformed porous body with molten metal is normally accomplished by applying pressure or a vacuum to facilitate penetration of the liquid metal into the voids. Also, this process can be achieved through a pressureless infiltration process - that is - without the application of external force. The external force required for infiltration operation can be provided by a hydraulic or mechanical press with a heater or from gas pressure. Infiltration methods are classified based on sources of external force: pressureless infiltration method; gas pressure infiltration method; pressure die infiltration method; and squeeze casting infiltration method.

Several successful studies on pressureless infiltration have been reported, and the process has been modelled in many studies [39-41]. According to capillary law, the infiltration pressure threshold, $\mathrm{P}_{0}$, is [42]:

$$
P_{0}=6 \lambda \gamma_{l v} \cos \theta\left(\frac{V_{p}}{\left(1-V_{p}\right)^{D}}\right)
$$

Oh, Cornie, and Russell, in their study, defined capillary pressure or infiltration threshold pressure $\left(\mathrm{P}_{0}\right)$ in terms of pore fraction of powder compact and particulate size [43]:

$$
P_{0}=\frac{6 \lambda \gamma_{l v} \cos \theta(1-\omega)}{D \omega}
$$

where $\theta$ is the contact angle; $\lambda$ is the geometry depended factor (assumed to be 1.4); $\gamma_{\mathrm{lv}}$ is the tension of liquid-vapour surface; $\mathrm{D}$ is the mean diameter of the particles; $\mathrm{Vp}$, is the volume fraction of the particulates; and $\omega$ is the void fraction in the preform.

\subsection{Gas pressure infiltration method}

Gas pressure infiltration method (GPIM) is a FGMMCs fabrication process by forcing a molten metal to penetrate a preformed dispersed phase using a pressurised gas. This method is 
applied in the manufacturing of large composite components. The method is suitable for noncoated fibres due to short interaction time of the fibres with the hot metal and ensures low destruction of the fibres. Figure 8 shows the schematic of a GPIM set up.

Boczkowska et al. in 2013, studied the impact of infiltration method on the mechanical properties and microstructure of FGAACs [45]. The FGMMCs specimens were produced by GPIM and pressure-vacuum infiltration at the same conditions of $\mathrm{Tp}=7000 \mathrm{C}, \mathrm{P}=4 \mathrm{MPa}, \mathrm{tD}=5 \mathrm{~min}$. The infiltration methods were applied to pressure on aluminium alloy melt to penetrate porous $\mathrm{Al}_{2} \mathrm{O}_{3}$ ceramics preforms. The chemical composition of the aluminium alloy is presented in Table 6 .

The ceramic preforms were produced by sintering of RA-207LS $\mathrm{Al}_{2} \mathrm{O}_{3}$ powder, provided by Alcan Chemicals. The aluminium oxide used chemical composition is presented in Table 7. The preforms have similar porosity, of about $72 \mathrm{vol} \%$, at same level and three types of polyurethane sponges, varying density and size of pores $(60,45$ and 30$)$ were used. This resulted to the production of varying pore sizes, from 300 to 1000, preforms.
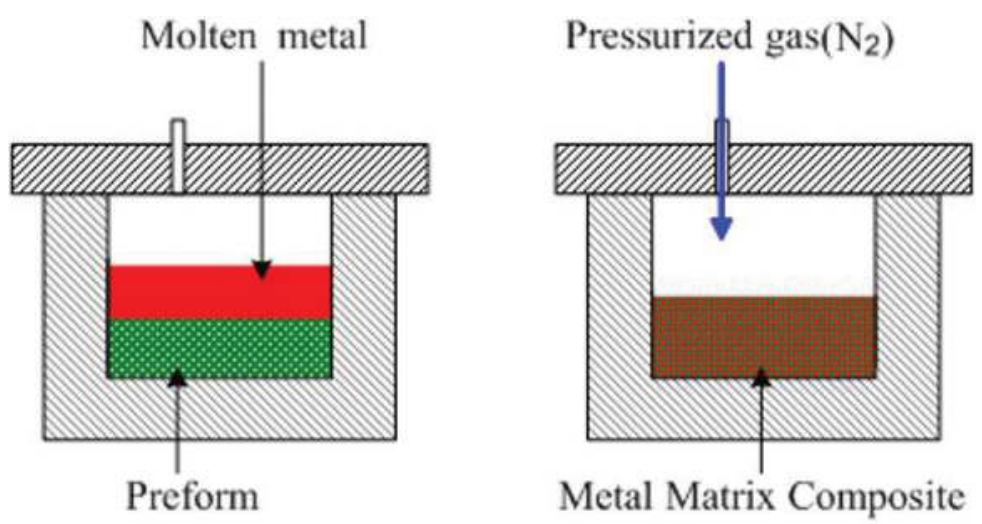

Figure 8. Schematic of a GPIM set-up [44].

\begin{tabular}{lllllll}
\hline Oxide & $\mathrm{Al}_{2} \mathrm{O}_{3}$ & $\mathrm{MgO}$ & $\mathrm{CaO}$ & $\mathrm{Fe}_{2} \mathrm{O}_{3}$ & $\mathrm{SiO}_{2}$ & $\mathrm{Na}_{2} \mathrm{O}$ \\
wt.\% & 99.8 & 0.04 & 0.02 & 0.03 & 0.04 & 0.07 \\
\hline
\end{tabular}

Table 6. Chemical composition of the aluminium oxide.

\begin{tabular}{lllllllllll}
\hline Element & $\mathrm{Al}$ & $\mathrm{Si}$ & $\mathrm{Fe}$ & $\mathrm{Mn}$ & $\mathrm{Cu}$ & $\mathrm{Mg}$ & $\mathrm{Ni}$ & $\mathrm{Zn}$ & $\mathrm{Ti}$ \\
wt.\% & 83.81 & 12 & 0.44 & 0.16 & 1.08 & 1.28 & 1.06 & 0.14 & 0.03 & \\
\hline
\end{tabular}

Table 7. AK12 cast aluminium alloy's chemical composition. 
The study observed that:

i. The Preforms with the smallest size of pores shown better degree of infiltration in in both infiltration methods.

ii. The specimens from both methods showed higher compressive strength, hardness, and Young's modulus.

iii. Composites fabricated by GPI smallest pores size preform possessed better mechanical properties.

iv. The compressive strength, Young's modulus and hardness improvements were proportional to the increase of the specific surface section of the interphase frontiers.

Per the study, the flow of metal within the preforms hangs on the size of capillary; the pressure difference along the length of capillary; the preserving time of molten metal state in the capillary; and the alloy's dynamic viscosity.

\subsection{Pressure die infiltration}

Pressure die infiltration method (PDIM) involves the forcing of MMCs liquid phase to penetrate into a preformed dispersed phase placed in a die by applying die casting technology. The molten metal, is ejected through the spruce, under the pressure of a movable plunger to penetrate the preform. The schematic of PDIM is shown in Figure 9.

\subsection{Squeeze casting infiltration}

Squeeze casting infiltration method (SCIM) is similar to the squeeze casting technique used for pure metals and their alloys. In SCIM, however, a hydraulic or mechanical press is required to

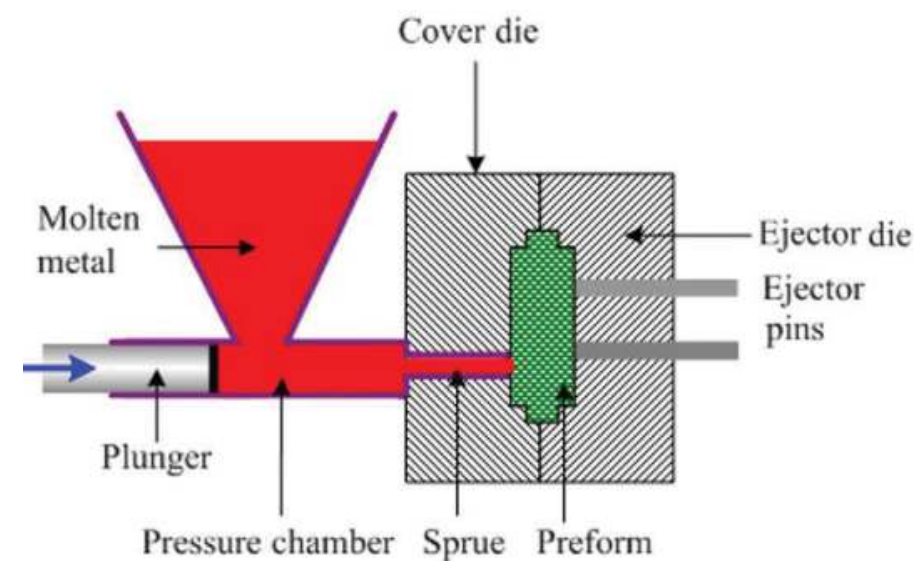

Figure 9. Schematic of PDIM. 
apply external force on the melt to penetrate the preform pores. As shown is Figure 10, the press may be with or without a heating unit; however, one with a heating unit is preferred. The heating unit is used to heat up and to keep the die at a required temperature before pouring. In additional to SCT processing parameters, preform temperature (Tf) is a factor to be considered in SCIM.

\subsubsection{Preform}

Preform is a rigid, porous body, containing a discontinuous of one or mixture more reinforcement materials. Production of a preform has three fundamental steps [46]: processing of liquid powder, pressing and shaping, and sintering the preform. The concept behind a preform is the combination of a ceramic powder slurry and a sacrificial organic pore forming agent (PFA) that will undergo pyrolysis. The thermochemical decomposition of organic in the absence of oxygen at high temperatures is termed pyrolysis. The blend of ceramic powder slurry and PFA is pressed and sintered to pyrolyse the PFA in order to form preform voids. The properties of a preform can be controlled by the following processing parameters: the type of pore forming agent (PFA), the green pressing pressure and the green sintering temperature. Examples of PFAs are carbon fibres (PF) and cellulose particles (PC). Table 8 presents some PFAs and their sintering temperature.

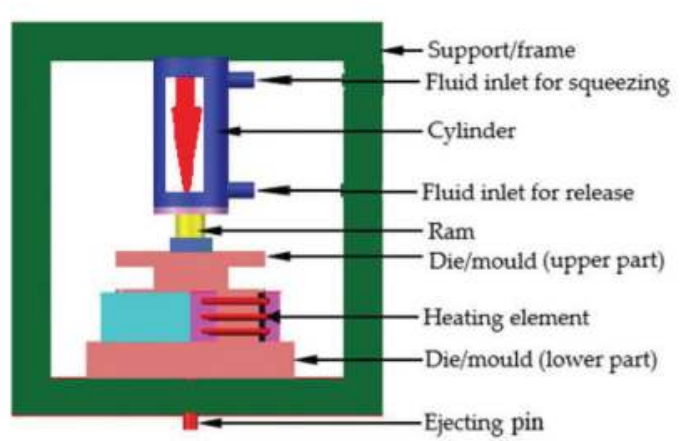

(a)

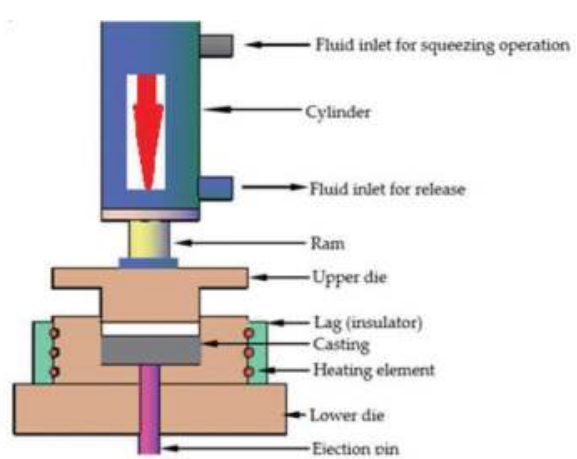

(b)

Figure 10. Schematic of hydraulic or mechanical press: (a) SCIM assembly with heating unit and (b) SCIM exploded diagram.

\begin{tabular}{lll}
\hline Ceramics & $\begin{array}{l}\text { Pore forming } \\
\text { additives }\end{array}$ & Sintering temperature $\left({ }^{\circ} \mathrm{C}\right)$ \\
\hline $\mathrm{AO}$ & $\mathrm{PF}$ & 1500 \\
$\mathrm{AO}$ & PC & 1600 \\
$\mathrm{Al}_{2} \mathrm{O}_{3}$ & Glassy frit binder $(\mathrm{AG})$ & 1000 \\
\hline
\end{tabular}

Table 8. Sintering temperatures for different preform formation $[47,48]$. 
In a study, ceramic preforms were produced by compressing a blended $\mathrm{Al}_{2} \mathrm{O}_{3}$ Condea CL 2500 powder and PFA in the form of carbon fibres and followed by sintering [49]. The chemical composition of $\mathrm{Al}_{2} \mathrm{O}_{3}$ Condea CL 2500 powder is presented in Table 9. The profile of the sintering process is presented in Figure 11.

\subsection{Centrifugal casting}

The filling of a rotating mould with a molten metal and allowing the melt to solidify before the spinning is stopped describes fabrication of FGM by centrifugal casting technique (CCT). The rotation creates force that pushes the molten metal outwards from the rotating axis. This process creates a centrifuge in a fluid and separate the fluid's constituents into regions based on density difference. The denser constituent migrates to the outer region. This method was first used by a Brazilian, Dimitri Sensaud DeLavaud, in 1918 [50]. Subsequently, this concept has been adapted in the casting of FGMs, aluminium alloys, corrosion and heat-resistant steels, copper alloys, etc. Its use is also found in the production of non-metal such as plastics, ceram-

\begin{tabular}{llllllll}
\hline Diameter D50 $\mu \mathrm{m}$ & \multicolumn{7}{l}{ Mean mass concentration of elements, wt. $\%$} \\
\cline { 2 - 8 } & $\mathrm{Al}_{2} \mathrm{O}_{3}$ & $\mathrm{Fe}_{2} \mathrm{O}_{3}$ & $\mathrm{CaO}$ & $\mathrm{SiO}_{2}$ & $\mathrm{Na}_{2} \mathrm{O}$ & Others \\
\hline 1.80 & 99.80 & 0.02 & 0.01 & 0.01 & 0.05 & 0.10 \\
\hline
\end{tabular}

Table 9. Chemical composition and particle diameter of $\mathrm{Al}_{2} \mathrm{O}_{3}$ Condea CL 2500 powder [49].

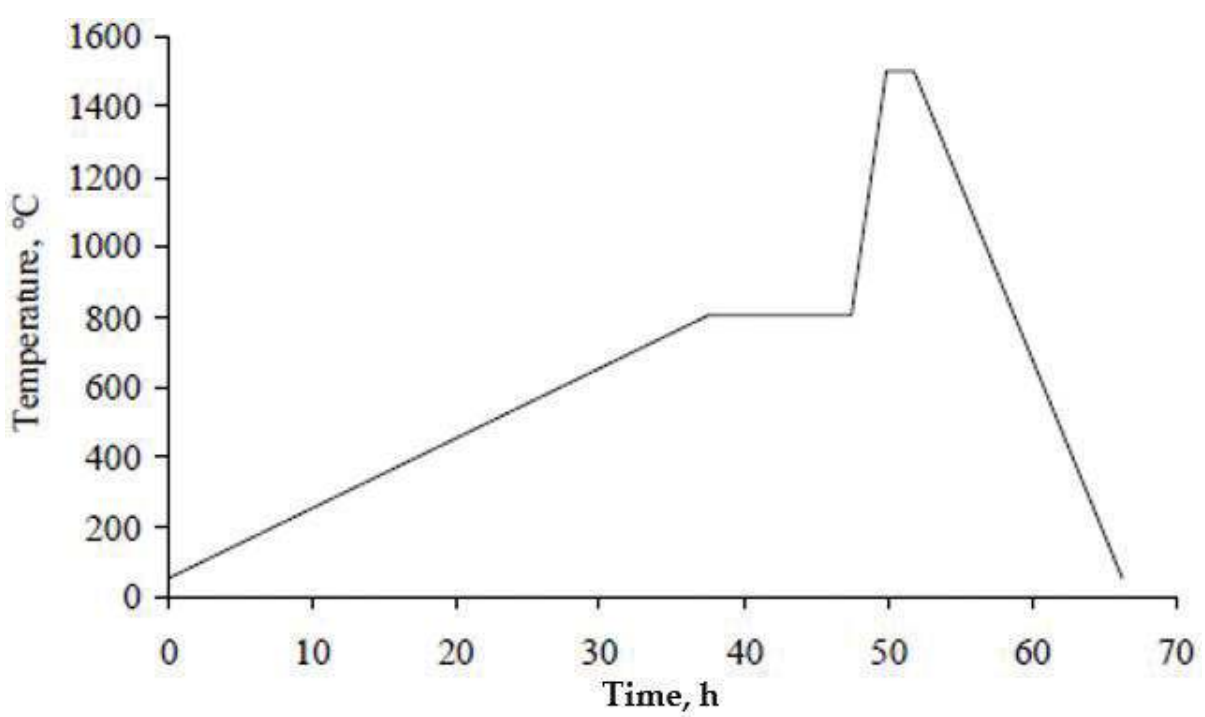

Figure 11. Temperature performance during the sintering process [49]. 
ics, glasses, and practically every material that is based on liquid or slurries forging method. A schematic of a centrifugal casting machine is shown in Figure 12.

In the centrifugal casting of hypereutectic Al-Si alloys, such as A390-5\%Mg, the outer region is formed by fibrous silicon. The large $\alpha$-aluminium dendrites and large primary silicon occupy the inner region due to similarity in their densities. Such castings are regarded as FGAACs. The fabrication of FGMs by CCT is characterised by the discontinuous distribution of reinforcements in a radially graded pattern. The metal matrix and reinforcement density difference cause segregation in which the particles with higher density move to the outer region and lower density particles migrate to the inner surface. The grading defines the functionality and can be controlled and improved by processing variables such as centrifugal rotation speed, molten metal alloying temperature, particle size and volume, mould temperature, and cast geometry [51].

\subsubsection{Classification of CCT}

The centrifugal casting process can be classified according to mould arrangement and angle inclination of mould to either vertical or horizontal planes [50], as shown in Figure 13; and based on the liquidus temperature of the matrix alloy. There are two types of centrifugal methods based on the liquidus temperature [52]: the ex situ or solid-particle centrifugal method; and the centrifugal in situ method.

\subsubsection{Forces acting on particle in a melt}

In CCT, the force generated primarily depends on the speed of mould rotation. Considering a vertical centrifugal casting, a particle suspended in molten metal is subjected to four types of

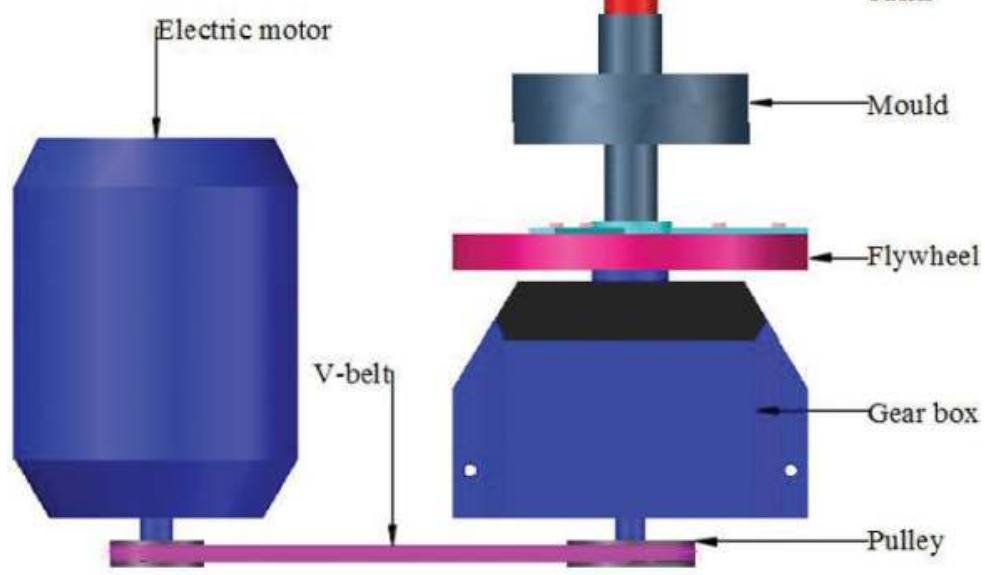

Figure 12. Schematic of a vertical centrifugal casting machine [46]. 


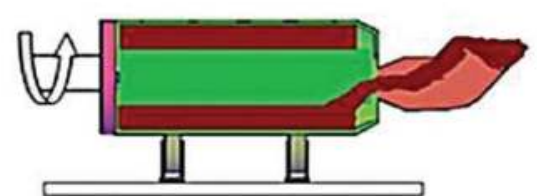

a) Horizontal true centrifugal casting process

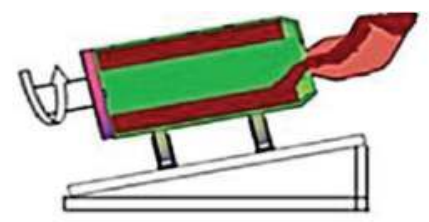

b) Horizontal inclined centrifugal casting process

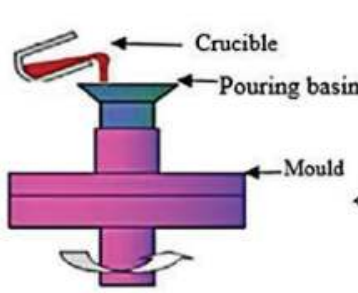

c) Vertical true centrifugal casting process

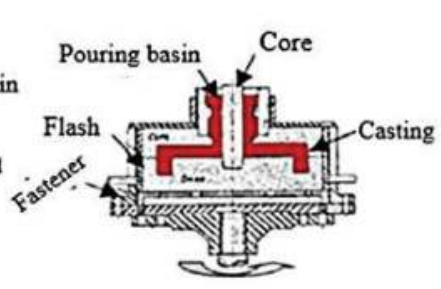

d) Semi vertical centrifugal casting process

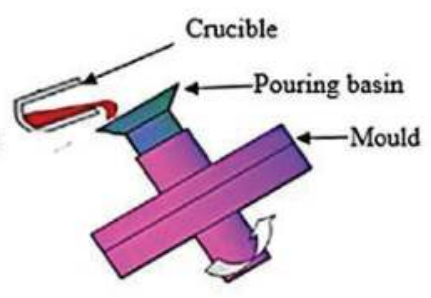

e) Vertical inclined centrifugal casting process

Figure 13. Classification of centrifugal casting methods based on mould rotation [50].

forces, as represented in Figure 14: centrifugal force caused by mould rotation, FC; drag force due to viscosity effect, FD; gravitational force, FG; and repulsive force or van der Waal forces caused by solid-liquid interface movement, FL. Force of gravity is often neglected because it is very small compared to centrifugal force [53-55].

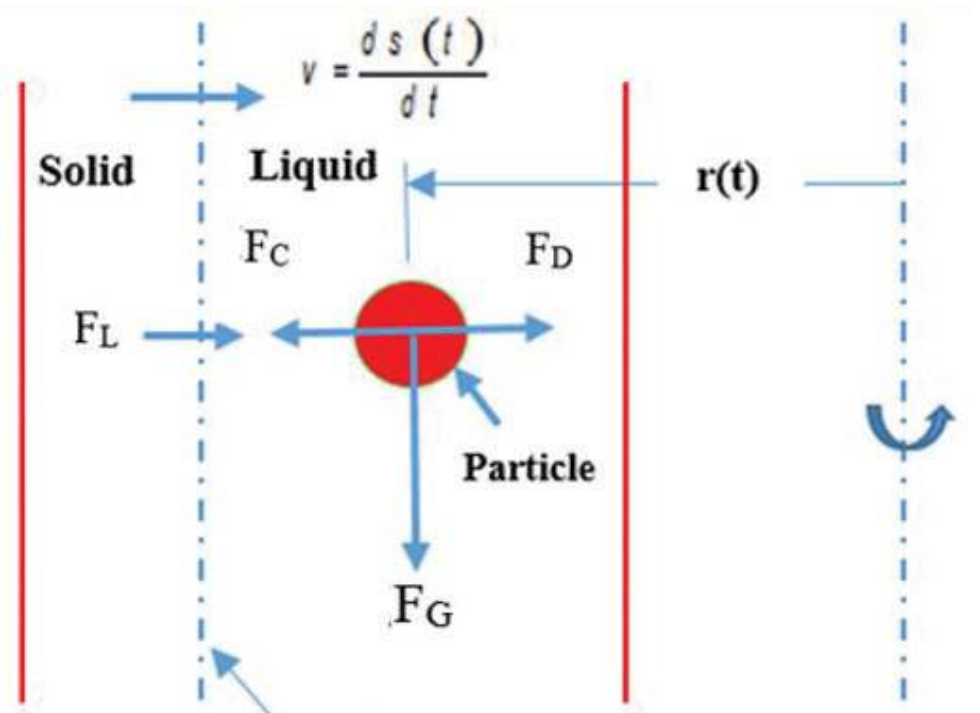

Interface

Figure 14. Forces acting on a particle moving in molten metal. 
Force balance equation, $\mathrm{F}_{\text {net }}$.

The force balance expression, $\mathrm{F}_{\text {net }}$ is estimated as:

$$
F_{n e t}=F_{C}-F_{D}-F_{L}
$$

The FL is linked to the particles within a solid-liquid interface or solid wall. The dynamic Fnet that is not induced by solid wall/interface is:

$$
F_{n e t}=F_{C}-F_{G}
$$

The Fnet equation assuming that the fluid flow is laminar $(\operatorname{Re} \leq 1)$ is:

$$
4 / 3 * \pi * R^{3} * \rho_{P}\left(d^{2} r / d t\right)=4 / 3 * \pi * R^{2}\left(\rho_{P}-\rho_{m}\right) \omega^{2} * r-6 * \pi * R * \mu(d r / d t)
$$

The solution of Fnet without FL of a particle at a given position moving at uniform velocity at any given time, $\mathrm{t}$, is:

$$
r(t)=r_{0} \exp \left[\frac{4 \omega^{2}\left(\rho_{P}-\rho_{m}\right) R^{2} t}{18 \mu}\right]
$$

Where $\mathrm{r} 0=$ position of the particle at time $\mathrm{t}=0$.

\subsubsection{Application of CCT}

In a study, Ramadan and Omer fabricated FGAACs of varying fraction volumes of boron $(1.2 \%$ to $1.85 \% \mathrm{wt}$ ), dispersed in $\mathrm{Al}, \mathrm{Al}-\mathrm{Cu}$, and $\mathrm{Al}-\mathrm{Si}$ alloys matrixes respectively, using CCT [56]. It was observed that $\mathrm{B}$ could only dissolve in aluminium alloys sufficiently at elevated temperature. Consequently, the source of boron, $\mathrm{B}_{2} \mathrm{O}_{3}$, was mixed with aluminium alloys at $1400^{\circ} \mathrm{C}$ and held for 30 minutes. Centrifugal casting was performed at $800^{\circ} \mathrm{C}$. The study reported that two regions were identified without smooth gradient, as shown in Figure 15, outer zone with AlB2

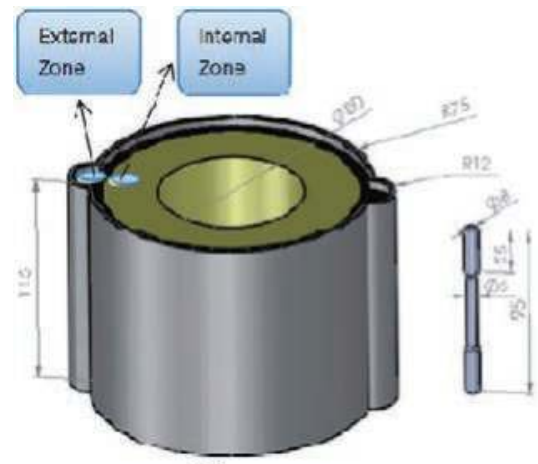

(a)

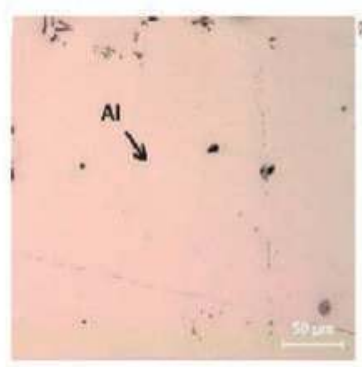

(b)

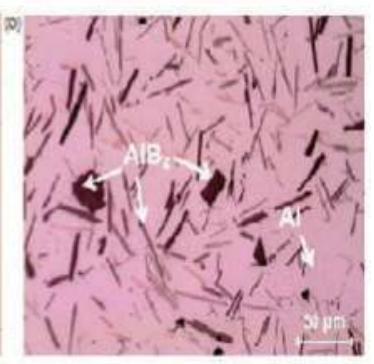

(c)

Figure 15. (a) Centrifugal casting mould for $\mathrm{Al}^{-\mathrm{AlB}_{2}}$ FGAAC (a) internal area and (b) external area [56]. 
surplus and inner zone with AlB2 deficit. Further, hardness of $64 \%$ and strength increase were observed with reinforcement particles volume fraction increase at the outer region.

In an investigative study, a complex shape component, a Pelton turbine bucket, was produced from FGAACs using CCT [57]. Functionally graded materials specimen, A356 alloy and A356$10 \% \mathrm{SiCp}$, were given T6 heat treatment. The study reported that the concentration of $\mathrm{SiCp}$ particles was higher at the inner periphery of the bucket. This was attributed to the Pelton turbine bucket mould design and arrangement. The heat treated specimens shown an appreciable hardness increase. The Pelton turbine bucket mould configuration is shown in Figure 16.

\subsection{Stir casting}

The liquid state technique of fabricating MMCs by mechanical means of mixing of molten metal matrix with the reinforcing particles (dispersed phase) is termed as stir casting. The schematics of a stir casting set-up as well as a complete stir casting facility are shown in Figure 17. This method has been described as the simplest and the most effective technique of liquid state production. The stir casting is made up of liquid phase (matrix) and the dispersed phase, which is limited to $30 \mathrm{vol}$ \%. Gravity may cause the reinforcement to segregate due to dispersed and matrix phase density difference. Furthermore, dispersed particles (fibres) form local clouds (clusters). These reasons are why the dispersed phase is not uniform (homogeneous). However, the uniformity of the dispersed phase may be improved when stirring process is conducted in a semi-solid state and this process is called Rheocasting.

The introduction of particles into the melt is an important step in FGAACs fabrication and can be achieved in multiple ways. These methods include inserting particles by an injection gun; adding the particles to the melt stream during pouring; pushing particles into the molten metal with a reciprocating piston; spraying atomised particles and molten metal on a substrate, vortexing, and so on. Vortexing is regarded as the most effective approach towards inserting particles into the molten metal and ultimately dispersing and suspending the dispersed phase in the slurry. The introduction of stirring process is done after the matrix has melted. Vigorous
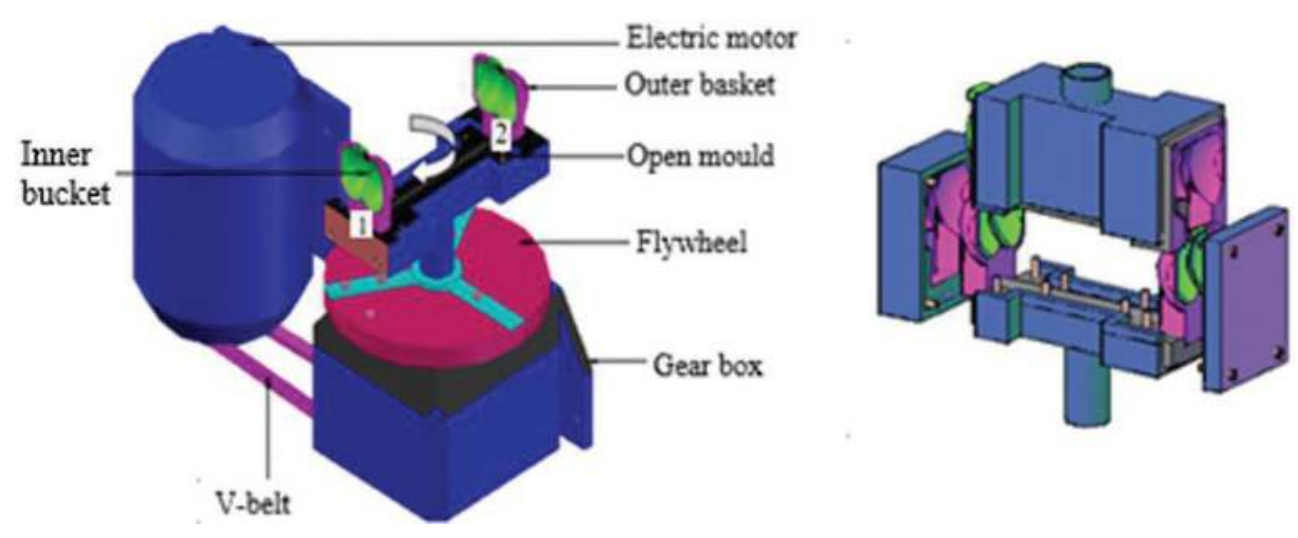

Figure 16. Centrifugal casting machine showing the configuration of the mould [57]. 
(a)

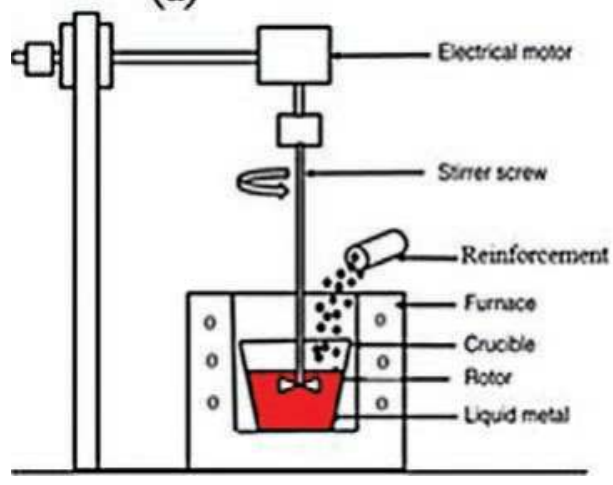

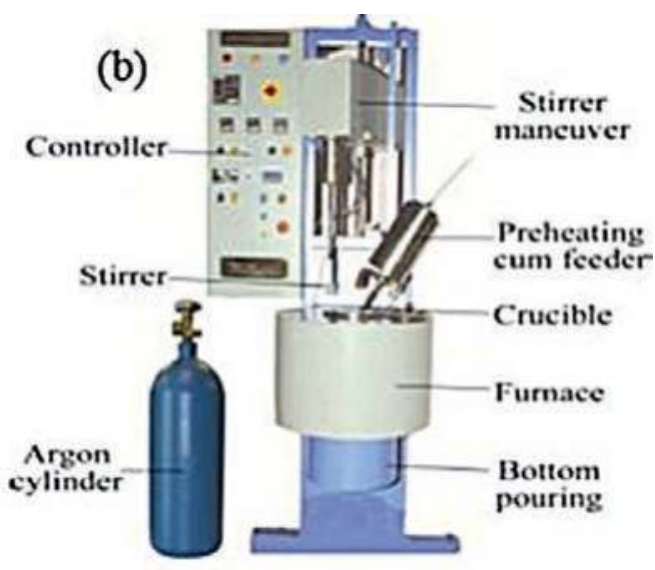

Figure 17. (a) A schematic stir casting set-up and (b) a complete stir casting facility [58].

stirring is required for the formation of vortex at the matrix melt surface. The particles are inserted into the matrix through the vortex and stirred for few minutes before the slurry mixture is poured into the mould. Stir casting is affected by certain variables, such as stirring time, pouring temperature, pouring rate, stirrer blade angle, and gating systems $[58,59]$.

\subsection{Compocasting}

Many wettability enhancement methods have been introduced and some of these methods include the use of wettability agents and fluxes, preheating, oxidation and ceramic coating $[60,61]$. The application of some of these techniques is expensive. However, the compocasting method is an economical technique to improve wettability [62]. Compocasting, or slurry casting, is a liquid state process in which the dispersed phase is added to a solidifying melt under a vigorously agitation. This method prevents agglomeration and the gravity induced reinforcement segregation by mechanically entrapping the dispersed phase in the semi-solid slurry. Further, the reinforcing particles are better distributed, and gives lower porosity casting $[63,64]$. The better wettability between the matrix and the dispersed phase, and matrix alloy lower volume shrinkage are accountable for the lower porosity.

Compocasting liquid state process technology is undergoing review and the investigative study on the process is expanding due to its increase in applications. Gladston et al. produced AA6061-RHAp, rice husk ash particle composite, via the compocasting method [61]. Formation of intergranular distribution of particles and the enhancement of macro hardness and ultimate tensile strength of RHA particles of FGAAC were observed. Poor mechanical properties of Al-Si alloys have been attributed to the challenges of homogeneous dispersion of SiCp particles and the non-uniform distribution of coarse Si fibres in the matrix. The use of an accumulative roll bonding (ARB) technique, which operates on the concept of the compocasting technique, eliminates these setbacks [65]. This was used to produce MMC with finer and spheroidal Si particles; minimised porosity; no Si and $\mathrm{SiC}$ particles free zone; better matrix-particle bonding; and evenly dispersed $\mathrm{Si}$ and SiCp particles. The schematic of ARB is shown in Figure 18. 


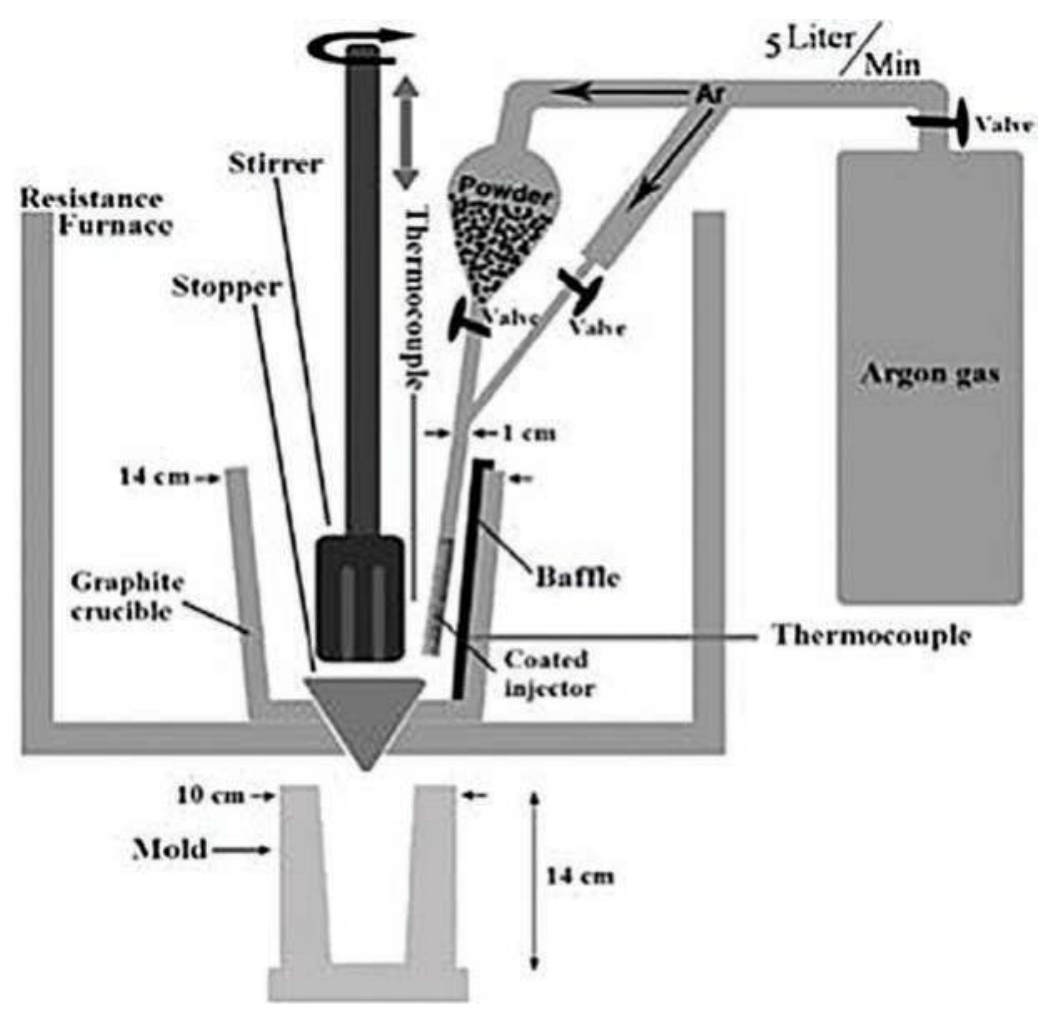

Figure 18. Schematic of ARB set-up [65].

\section{Effects of wettability and porosity in FGMs}

\subsection{Wettability}

Several barriers prevent FGAACs from performing in their full potentials, and one paramount among them is insufficient wetting of reinforcing particles by molten aluminium. The spreading of a liquid on the solid surface is defined as wettability and has been linked to close contact between a liquid and a solid. The way in which the dispersed phase is wetted by melt is a sign of success of particle insertion into the matrix in FGAAC fabrication. The aluminium oxide layer which covers molten aluminium and/or the inherent silicon oxide that covers $\mathrm{SiC}$ particles is responsible for the inadequate wetting of $\mathrm{SiC}$ particles by molten aluminium. Reactive elements, such as $\mathrm{Ti}, \mathrm{Zr}, \mathrm{Ca}, \mathrm{Mg}$, etc. are added to metal matrix to stimulate wettability of matrix on reinforcements.

The relation between bonding force of the matrix and the particles was described by Young Dupre's equation in terms of contact angle $(\theta)$ as depicted in Figure 19 as follows [66]:

$\theta-0^{\circ}$ (Perfect wettability); $\theta-180^{\circ}$ (no wetting); $0<\theta<180^{\circ}$ (partial wetting). 


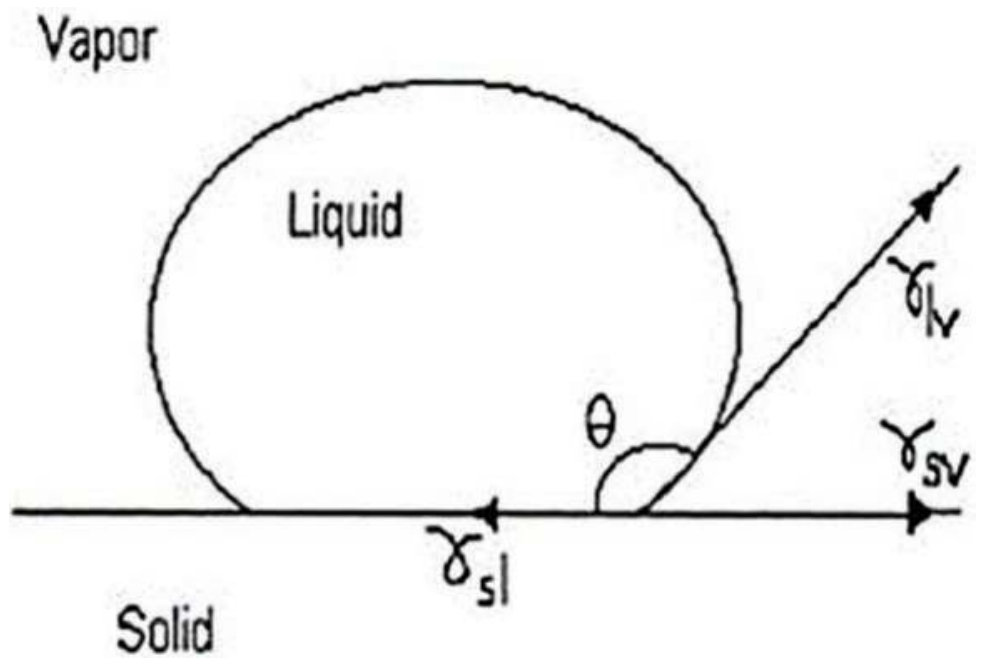

Figure 19. Schematic showing the contact angle between the liquid phase and the solid phase [59], where $\gamma_{\mathrm{sv}}$ is the solidvapour; $\gamma_{\mathrm{sl}}$ is the solid-liquid interfacial energy; and $\gamma_{\mathrm{lv}}$ is the liquid-vapour interfacial energy.

\subsection{Porosity}

Porosities are often seen as defects in engineering materials, unless the materials are deliberately designed to have pores for functionality, such as in biomedical materials, where porosity is useful for permeation of medical compounds. Other applications of porosity include filters, catalyst supports and furnace lining bricks. FGAAMCs are made dense to minimise porosity and to improve the mechanical properties of the materials. Damping capacity, the Poisson ratio, tensile and compressive strengths and Young's modulus of elasticity are inversely proportional to porosity. Porosity formation is caused by vapour from surfaces of reinforcement, air bubbles in a matrix melt, shrinkage during solidification and gas entrapment and hydrogen evolution [67]. Series of manufacturing techniques have been invented and appraised to minimise porosity in cast FGMs and these include: vacuum casting, casting under pressure, inert gas bubbling past the liquid metal, rolling of material after casting to close the voids, compressing, and addition of hexachloroethane to melt [68].

\section{Applications areas of FGMS}

The FGM concept is described as a systematic process of combining incompatible functions such as wear and corrosion resistance, thermal, toughness and machinability into a single part. This has expanded the application of FGMs in many sectors. Two FGMs in commercial status are high performer cutting tools, namely, tungsten carbide/cobalt and a razor blade of iron aluminium/stainless steel (FeAl/SS) FGM [6]. Table 10 presents FGMs application areas. 


\begin{tabular}{ll}
\hline Sectors & Applications \\
\hline Engineering & Cutting tools, machine parts, engine components, etc. \\
Medical & Biomaterials: implants, artificial skin, drug delivery system \\
Energy & Thermionic and thermoelectric converters, fuel cells and solar batteries \\
Aerospace & Space plane nose, combustion chamber protective layer, body components, etc. \\
Automotive & Crown of piston, cylinder liners, exhaust valves and valve seating \\
Nuclear & First wall of fusion reaction, fuel pellets \\
Optics & Optical fibre, lens \\
Chemical plants & Heat exchanger, heat pipe, slurry pump, reaction vessel \\
Electronics & Graded band semiconductor, substrate, sensor \\
\hline
\end{tabular}

Table 10. Application areas of FGMs.

\section{Conclusion}

This chapter presents an overview of the bulk FGMs production techniques, their evolution, principles and applications. The fabrication processes discussed include squeeze casting, compocasting, infiltration process, stir casting, and centrifugal casting. The chapter observed that despite the tremendous development in developing FGMs and their production technologies, challenges still abound in getting the desirable material without certain material attributes being a trade-off. The use of some of these methods for mass production is challenging from cost of fabrication perspective. However, the combination of techniques seems to be satisfactory as stir casting with compocasting, stir casting with squeeze casting processes. Several FGAAMCs laboratory investigations have revealed that processing parameters to consider are peculiar to the type of fabrication method used. However, reinforcement particle size, and casting temperature seem to be common to all the methods.

\section{Author details}

Williams S. Ebhota* and Tien-Chien Jen

*Address all correspondence to: willymoon2001@yahoo.com

Mechanical Engineering Department, University of Johannesburg, Johannesburg, South Africa

\section{References}

[1] Tarlochan F. Functionally graded material: A new breed of engineered material. Journal of Applied Mechanical Engineering. 2013;1:1-5 
[2] Rezaei Mojdehi A, Darvizeh A, Basti A, Rajabi H. Three dimensional static and dynamic analysis of thick functionally graded plates by the Meshless local Petrov-Galerkin (MLPG) method. Engineering Analysis with Boundary Elements. 2011;35(11):1168-1180

[3] Shailendra KB, Ritesh S, Prabhat RM. Functionally graded materials: A critical review. International Journal of Research (IJR). 2014;1:289-301

[4] Knoppers GE, Gunnink JW, Van Den Hout J, Vliet WPV. The Reality of Functionally Graded Material Products. Presented at the International Solid Freeform Fabrication Symposium. Texas: University of Texas at Austin; 2004

[5] Ebhota WS, Inambao FL. Principles and baseline knowledge of functionally graded aluminium matrix materials (FGAMMs): Fabrication techniques and applications. International Journal of Engineering Research in Africa. 2016;26:47-67

[6] Miyamoto Y, Kaysser W, Rabin B, Kawasaki A, Ford R. Functionally Graded Materials: Design, Processing and Applications. US Kluwer Academic Publishers; 1999

[7] Lannutti JJ. Functionally graded materials: Properties, potential and design guidelines. Composites Engineering. 1984;4:18-94

[8] Shukla A, Jain N, Chona R. A review of dynamic fracture studies in functionally graded materials. Strain. 2007;42:76-95

[9] Saifulnizan J. Application of Functionally Graded Materials for Severe Plastic Deformation and Smart Materials: Experimental Study and Finite Element Analysis; PhD. Department of Engineering Physics, Electronics and Mechanics, Graduate School of Engineering, Nagoya Institute of Technology, Japan; 2012

[10] Shen M, Bever MB. Gradient in polymetric materials. Materials Science and Engineering. 1972;7:741-746

[11] Bever MB, Duwez PF. Gradient in composite materials. Materials Science and Engineering. 1972;10:1-8

[12] Niino M, Hirai T, Watanabe R. The functionally gradient materials. Japan Society for Composite Materials. 1987;13:257-264

[13] Niino M, Kumakawa A, Watanabe R, Doi Y. Fabrication of a High Pressure Thrust Chamber by CIP Forming MethodMetal powder report 41, 663, 9.1986

[14] Ankit BM, Khushbu CP. A review of stress analysis of functionally graded material plate with cut-out. International Journal of Engineering Research \& Technology (IJERT). 2014;3

[15] Wang SS. Fracture mechanics for delamination problems in composite materials. Journal of Composite Materials. 1983;17:210-223

[16] Dalal R. Thermal Analysis of Functionally Graded Material (FGM) Plate Using Finite Element Method (FEM)M. Tech. Murthal: Mechanical Engineering, Deenbandhu Chhotu Ram University of Science and Technology; 2016 
[17] Siti NSJ, Faizal M, Dewan MN, Shah NB. A review on the fabrication techniques of functionally graded ceramic-metallic materials in advanced composites. Scientific Research and Essays. 2013;8:828-840

[18] Besmann TM. Proceedings of the Thirteenth International Conference on Chemical Vapor Deposition vol. 96-5. Pennington, New Jersey, USA: The Electrochemical Society, Inc., 1996

[19] Groves JF, Wadley HNG. Functionally graded materials synthesis via low vacuum directed vapor deposition. Composites Part B: Engineering. 1997;28:57-69

[20] Hutmacher DW, Sittinger M, Risbud MV. Scaffoldbased tissue engineering: Rationale for computer-aided design and solid freeform fabrication systems. Trends in Biotechnology. 2004;22:354-362

[21] Mumtaz KA, Hopkinson N. Laser melting functionally graded composition of Waspaloy and zirconia powders. Journal of Materials Science and Engineering. 2007;42:7647-7656

[22] Rasheedat MM, Esther TA, Mukul S, Sisa P. Functionally Graded Material: An Overview. In: Proceedings of the World Congress on Engineering, WCE, London, UK, 2012

[23] Jiang R, Chen X, Ge R, Wang W, Song G. Influence of TiB2 particles on machinability and machining parameter optimization of $\mathrm{TiB}_{2} / \mathrm{Al}$ MMCs. Chinese Journal of Aeronautics 20-04-2017. 2017

[24] Ibrahim A, Mohamed F, Lavernia E. Particulate reinforced metal-matrix composites-A review. Journal of Materials Science. 1997;26:1137-1156

[25] Rajan TPD, Jayakumar E, Pai BC. Developments in solidification processing of functionally graded aluminium alloys and composites by centrifugal casting technique. Transactions of the Indian Institute of Metals. 2012;65:531-537 01-12-2012

[26] Rajan TPD, Pai BC. Developments in processing of functionally gradient metals and metalceramic composites: A review. Acta Metallurgica Sinica (English Letters). 2014;27:825-838

[27] El-Galy IM, Ahmed MH, Bassiouny BI. Characterization of functionally graded Al-SiCp metal matrix composites manufactured by centrifugal casting. Alexandria Engineering Journal 27-03-2017. 2017. DOI: http://dx.doi.org/10.1016/j.aej.2017.03.009

[28] Tsiatas GC, Charalampakis AE. Optimizing the natural frequencies of axially functionally graded beams and arches. Composite Structures. 2017;160:256-266 15-01-2017

[29] Vieira AC, Rocha LA, and Gomes JR, Influence of Sic Particles Incorporation on the Microstructure and Tribological Behaviour of Functional Graded Al/SiCp Composites. In: Proceedings of the IV Iberian Congress on Tribology, Ibertrib, Bilbao, Spain, 2007

[30] Erdemir F, Canakci A, Varol T. Microstructural characterization and mechanical properties of functionally graded Al2024/Sic composites prepared by powder metallurgy techniques. Transactions of Nonferrous Metals Society of China. 2015;25:3569-3577 
[31] Vieira AC, Sequeira PD, Gomes JR, Rocha LA. Dry sliding wear of Al alloy/SiCp functionally graded composites: Influence of processing conditions. Wear. 2009;267:585-592

[32] Watanabe Y, Kawamoto A, Matsuda K. Particle size distributions in functionally graded materials fabricated by centrifugal solid-particle method. Composites Science and Technology. 2002;62:881-888

[33] Ghomashchi MR, Vikhrov A. Squeeze casting: An overview. Journal of Materials Processing Technology. 2000;101:1-9

[34] Total Materia (2007, 23-07-2017). Squeeze Casting Process: Part one. Available: http:// www.totalmateria.com/page.aspx?ID=CheckArticle\&site=ktn\&NM=172

[35] Li R, Liu L, Zhang L, Sun J, Shi Y, Yu B. Effect of squeeze casting on microstructure and mechanical properties of hypereutectic Al-xSi alloys. Journal of Materials Science and Technology. 2017;33:404-410 01-04-2017/

[36] Wang F, Ma Q, Meng W, Han Z. Experimental study on the heat transfer behavior and contact pressure at the casting-Mold Interface in squeeze casting of Aluminum alloy. International Journal of Heat and Mass Transfer. 2017;112:1032-1043 01-09-2017/

[37] Jahangiri A, Marashi SPH, Mohammadaliha M, Ashofte V. The effect of pressure and pouring temperature on the porosity, microstructure, hardness and yield stress of AA2024 Aluminum alloy during the squeeze casting process. Journal of Materials Processing Technology. 2017;245:1-6 01-07-2017/

[38] Kopeliovich D. Squeeze Casting; 2012(25-07-2017)

[39] Ibrahim IA, Mohamed FA, Lavernia EJ. Particulate reinforced metal matrix composites - A review. Journal of Materials Science. January 01 1991;26:1137-1156

[40] Meier A, Javernick DA, Edwards GR. Ceramic-metal interfaces and the spreading of reactive liquids. JOM. February 01 1999;51:44-47

[41] Gupta M, Ibrahim IA, Mohamed FA, Lavernia EJ. Wetting and interfacial reactions in Al-Li-SiCp metal matrix composites processed by spray atomization and deposition. Journal of Materials Science. December 01 1991;26:6673-6684

[42] Bear J. Dynamics of Fluids in Porous Media. New York: American Elsevier Publishing. Co; 1972

[43] OhSY, CornieJA, Russell KC. Wetting of ceramic particulates with liquid aluminum alloys: Part I. Experimental techniques. Metallurgical Transactions A. 01-03-1989;20:527-532

[44] D. Kopeliovich. 2012, (26-07-2017). Liquid State Fabrication of Metal Matrix Composites. Available: http://www.substech.com/dokuwiki/doku.php?id=liquid_state_fabrication_ of_metal_matrix_composites

[45] Boczkowska A, Chabera P, Dolata AJ, Dyzia M, Oziębło A. Porous ceramic-Metal composites obtained by infiltration methods. Meta. 2013;52:345-348 
[46] Ebhota WS, Karun AS, Inambao FL. Principles and baseline knowledge of functionally graded aluminium matrix materials (FGAMMs): Fabrication techniques and applications. International Journal of Engineering Research in Africa. 2016:47-67

[47] Staudenecker D. Development of Porous Ceramic Preforms and Manufacture of MetalCeramic Composites: Diploma FH Aalen. FH Aalen, Germany; 2001

[48] Bernd AH. Pressure Infiltration Behaviour and Properties of Aluminium Alloy - Oxide Ceramic Preform CompositesDoctor of Philosophy. School of Metallurgy and Materials, The University of Birmingham, UK; 2009

[49] Dobrzañski LA, Kremzer M, Nowak AJ, Nagel A. Aluminium matrix composites fabricated by infiltration method. Archives of Materials Science and Engineering. 2009;36:5-11

[50] Sufei W, Steve L. ASM handbook: Centrifugal casting. ASM International. 2008;15:667-673

[51] Ebhota WS, Karun AS, Inambao FL. Centrifugal casting technique baseline knowledge, applications, and processing parameters: Overview. International Journal of Materials Research. 2016;107:960-969

[52] Watanabe Y, Sato H, Fukui Y. Wear properties of intermetallic compound reinforced functionally graded materials fabricated by centrifugal solid-particle and in-situ methods. Journal of Solid Mechanics and Materials Engineering. 2008;2:842-853

[53] Balout B, Litwin J. Mathematical Modeling of particle segregation during centrifugal casting of metal matrix composites. Journal of Materials Engineering and Performance. 2012;21:450-462

[54] Emila P, Dipak M, Mehrotra SP. Mathematical Modeling of particle segregation during centrifugal casting of metal matrix composites. Metallurgical and Materials Transactions. 2006;37A:1675-1687

[55] Rempel AW, Worster MG. Particle trapping at an advancing solidification front with interfacial-curvature effects. Journal of Crystal Growth. 2001;223:420-432

[56] Kayikci R, Savaş Ö. Fabrication and properties of functionally graded Al/AlB2 composites. Journal of Composite Materials. 2015;49:2029-2037

[57] Ebhota WS, Karun AS, Inambao FL. Investigation of functionally graded aluminium A356 alloy and A356-10\%SiCp composite for hydro turbine bucket application. International Journal of Engineering Research in Africa. 2016;26:30-46

[58] Jebeen MJ, Dinaharan I, Joseph SS. Prediction of influence of process parameters on tensile strength of AA6061/TiC Aluminum matrix composites produced using stir casting. Transactions of Nonferrous Metals Society of China. 2016;26:1498-1511

[59] Hashim J, Looney L, Hashmi MSJ. Metal matrix composites: Production by the stir casting method. Journal of Materials Processing Technology. 1999;92-93:1-7

[60] Ashok KB, Murugan N. Metallurgical and mechanical characterization of stir cast AA6061-T6-AlNp composite. Materials and Design. 2012;40:52-58 
[61] Allwyn KGJ, Mohamed SN, Dinaharan I, David RSJ. Production and characterization of rich husk ash particulate reinforced AA6061 aluminum alloy composites by compocasting. Transactions of Nonferrous Metals Society of China. 2015;25:683-691

[62] Ceschini L, Minak G, Morri A. Tensile and fatigue properties of the AA6061/20 vol.\% $\mathrm{Al}_{2} \mathrm{O}_{3} \mathrm{p}$ and $\mathrm{AA} 7005 / 10$ vol. $\% \mathrm{Al}_{2} \mathrm{O}_{3} \mathrm{p}$ composites. Composites Science and Technology. 2006;66:333-342

[63] Dinaharan I, Nelson R, Vijay SJ, Akinlabi ET. Microstructure and wear characterization of aluminum matrix composites reinforced with industrial waste fly ash particulates synthesized by friction stir processing. Materials Characterization. 2016;118:149-158 01-08-2016

[64] Hoziefa W, Toschi S, Ahmed MMZ, Morri A, Mahdy AA, El-Sayed Seleman MM, et al. Influence of friction stir processing on the microstructure and mechanical properties of a compocast AA2024- $\mathrm{Al}_{2} \mathrm{O}_{3}$ nanocomposite. Materials \& Design. 2016;106:273-284 15-09-2016

[65] Amirkhanlou S, Roohollah J, Behzad N, Mohammad RT. Using ARB process as a solution for dilemma of $\mathrm{Si}$ and SiCp distribution in cast Al-Si/SiCp composites. Materials Process Technology. 2011;211:1159-1165

[66] Narciso J, AIonso A, Pamies A, Garcia-Cordovilla C, Louis E. Wettability of binary and ternary alloys of the system Al-Si-Mg with SiC particulates. Scripta Metallurgy. 1994;31:1495-1500

[67] Aqida SN, Ghazali MI, Hashim J. Effects of porosity on mechanical properties of metal matrix composite: An overview. Jurnal Teknologi. 2004;40:17-32

[68] Larry LH. Bioceramics. Journal of the American Ceramic Society. 1998;81:1705-1728 